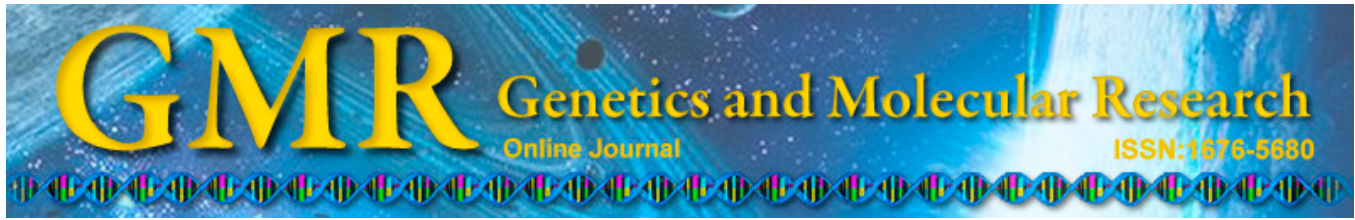

\title{
Genetic diversity of different populations and improved growth in the F1 hybrids in the swimming crab (Portunus trituberculatus)
}

\author{
B.Q. Gao ${ }^{1,2}$, P. Liu ${ }^{1}$, J. Li ${ }^{1}$, Q.Y. Wang ${ }^{1}$ and X.P. $\mathrm{Li}^{1}$ \\ ${ }^{1}$ Yellow Sea Fisheries Research Institute, \\ Chinese Academy of Fishery Sciences, Qingdao, China \\ ${ }^{2}$ College of Marine Life Sciences, Ocean University of China, Qingdao, China \\ Corresponding author: P. Liu \\ E-mail: liuping@ysfri.ac.cn
}

Genet. Mol. Res. 13 (4): 10454-10463 (2014)

Received April 7, 2014

Accepted September 2, 2014

Published December 12, 2014

DOI http://dx.doi.org/10.4238/2014.December.12.7

\begin{abstract}
The swimming crab, Portunus trituberculatus, is widely distributed throughout the coastal waters of Asian-Pacific nations and is an important economic species in this region. The aquaculture of swimming crabs has been plagued by problems associated with low growth rates, poor flesh quality, and weak disease resistance. To overcome these problems, selective breeding programs have been suggested as a means of genetically improving these traits in stock populations. In this study, we evaluated the genetic differentiation of 3 different geographical populations (Zhoushan: S; Laizhou Bay: L; and Haizhou Bay: H) using 8 polymorphic microsatellite loci. Nine strains of first filial generation were obtained, with 3 geographically populations as parental stock. We assessed the growth and survival rates of the F1 generation to identify new strains or breeds showing improvements in these economically important traits. Our results indicated that pairwise $F_{\mathrm{ST}}$ among populations was significantly higher than $0(\mathrm{P}$ $=0.0000$ ) for every population pair, ranging from 0.0810 to 0.1083
\end{abstract}


for 3 different geographical populations. We observed significant heterosis for the growth and viability (survival) traits, although some strains (crossbred combinations) showed evidence of hybrid weakness in some growth measurements. One particular strain ("SL") outperformed other combinations, displaying the greatest extent of heterosis over the growth and viability (survival) traits. These results indicate that hybridization may be used to increase the performance of $P$. trituberculatus in aquaculture.

Key words: Portunus trituberculatus; Geographic population; Heterosis; Genetic differentiation; Crossbreeding

\section{INTRODUCTION}

The swimming crab Portunus trituberculatus is widely distributed throughout the coastal waters of the Asia-Pacific region and has become an important economic species for countries in this region. In China, farming of $P$. trituberculatus produces annual yields of up to 100,000 tons (FBMAPRC, 2010). Since its inception two decades ago, commercial crab farming has largely depended on the supply of wild seed stock, which is often unreliable or limited (Wang et al., 2006). In addition, the characteristics of commercially farmed stocks (e.g., growth rates, flesh quality, and degree of disease resistance) have declined after many generations of culturing. To overcome these limitations and improve the sustainability of the crab culture industry, selective breeding programs have been undertaken to genetically improve growth rates and disease resistance characteristics. Breeding programs are based on utilizing genetic variation for economically important traits that exist in different geographic populations by creating inter-population hybrids. These hybrids are expected to show heterosis (hybrid vigor) for growth and viability.

Inter-specific hybridization and intra-specific crossbreeding may improve the viability of domestic animals through non-additive genetic effects (Misamore and Browdy, 1997). Generally, hybrids of different populations have better performance than the purebred of their parents in growth rate, fecundity, and adaptability. However, the maximum dominance advantage is present primarily in the first generation (F1), some of which will be lost in subsequent generations. In addition, studies show that hybrid offspring exhibit a loss of the epistatic superiority from pure breeds because of the segregation and recombination of gametes from the crossbred parents. Moreover, inter-species hybridization can produce sterile progeny or combine the unwanted characteristics of the parental species. However, the sterile descendants of hybridization can help protect native species and avoid gene introgression; the spawn rate, hatch rate, and survival rate of inter-species hybrids are generally lower than in the offspring resulting from intra-species mating (Tian et al., 2008). To date, few attempts to create inter-species hybrids in aquaculture have been successful (Lin et al., 1988; Lawrence et al., 1994). Intra-species crossbreeding to exploit the effects of heterosis is relatively common in aquaculture both in fish production [e.g., in tilapia (Oreochromis niloticus), carp (Cyprinus carpio), and catfish] (Colleen et al., 2004) and in the farming of crustaceans (Benzie et al., 1995; Cruz and Ibarra, 1997; English et al., 2000; Bierne et al., 2000; Liu et al., 2003). The use of crossbreeding for heterosis and genetic improvement of stocks has not been exploited in the farming of swimming crab, although an evaluation of the morphological dif- 
ferences between different populations has been conducted (Gao et al., 2007). In this study, we evaluated the genetic differentiation of 3 wild populations using 8 polymorphic microsatellite loci. Next, hybrid vigor was evaluated in swimming crab hybrids produced by crossing individuals obtained from 3 different geographical populations (Zhoushan: S; Laizhou Bay: L; and Haizhou Bay: H). We assessed the growth and survival rates of the F1 generation to identify new strains or breeds showing improvements in these economically important traits, and thus those that had the potential to enhance the quality and sustainability of aquaculture practices for the swimming crab.

\section{MATERIAL AND METHODS}

\section{Study population}

Swimming crabs from 3 wild, geographically distinct Chinese populations were used as parental stock (S, L, and H). We got the permission from the Zhoushan, Laizhou Bay, and Haizhou Bay Fishery Management Council. The swimming crab is not an endangered or protected species in China, which can be used for breeding materials. All the experimental animal programs involved in this study were approved by Committee of Yellow Sea Fisheries Research Institute, and followed the experimental basic principles. All mating and crosses among these stocks were conducted at the facilities of Changyi Haifeng Aquiculture Ltd. in Weifang from 2006 to 2007.

\section{Genomic DNA extraction and microsatellite analysis}

Genomic DNA was obtained from the claw muscle using the phenol/chloroform extraction method as described previously (Liu et al., 2000). Eight microsatellite markers (Table 1) were used to analyze the genetic differentiation of 3 wild populations (L, S, and $\mathrm{H})$. Primer sequences, microsatellite core sequence, and optimum polymerase chain reaction (PCR) amplification conditions are shown.

Table 1. Sequences of 8 microsatellite primer pairs in 3 populations of Portunus trituberculatus.

\begin{tabular}{|c|c|c|c|c|}
\hline No. clone (locus) & Primer sequence $\left(5^{\prime}-3^{\prime}\right)$ & Core repeats & GenBank accession & $\begin{array}{c}\text { Annealing } \\
\text { temperature }\left({ }^{\circ} \mathrm{C}\right)\end{array}$ \\
\hline PTR33a & $\begin{array}{l}\text { F: ACAACGCCAACAATAGCA } \\
\text { R: CACCGCACTTTACAGCAC }\end{array}$ & $(\mathrm{CT})_{16} \ldots(\mathrm{GT})_{39}$ & GQ466030 & 63.0 \\
\hline PTR45 & $\begin{array}{l}\text { F: AGAGGAGTGACTGGAGGGTA } \\
\text { R: TAAGGCTAAGGACAGGATGA }\end{array}$ & $(\mathrm{AC})_{15} \ldots(\mathrm{CA})_{11}$ & GQ466032 & 63.0 \\
\hline PTR93 & $\begin{array}{l}\text { F: AAGACAAAGCGACAAGCC } \\
\text { R: CGCAATAACTCCCAACAA }\end{array}$ & $(\mathrm{TG})_{9} \ldots(\mathrm{TG})_{33}$ & GQ466039 & 56.0 \\
\hline PTR95 & $\begin{array}{l}\text { F: CCTTGCCTTTCACTATACAC } \\
\text { R: GACCCACTTGTTATCGTTTT }\end{array}$ & $(\mathrm{GT})_{31} . .(\mathrm{CCT})_{5} \ldots(\mathrm{TCA})_{5}(\mathrm{TCT})_{6}$ & GQ466041 & 58.7 \\
\hline PTR98a & $\begin{array}{l}\text { F: GGATGAAGAGGAGGACTG } \\
\text { R: TGGTGGAGGATTATGAGA }\end{array}$ & $(\mathrm{CTA})_{7} \ldots(\mathrm{CTA})_{14} \ldots(\mathrm{TC})_{31}$ & GQ466042 & 56.0 \\
\hline PTR103b & $\begin{array}{l}\text { F: GGAGTGTTGGTGGTGGGT } \\
\text { R: AGGATTGGTATGCCGAGA }\end{array}$ & $(\mathrm{GT})_{28} \ldots(\mathrm{TGT})_{8}$ & GU177171 & 61.5 \\
\hline PTR112 & $\begin{array}{l}\text { F: AGGACCAGTGCCAACCAA } \\
\text { R: TTCACGCAGCCCATCTTC }\end{array}$ & $(\mathrm{GT})_{34} \ldots(\mathrm{CT})_{28}$ & GU177179 & 61.5 \\
\hline PTR145 & $\begin{array}{l}\text { F: ATCGTCATCGCCGAATAA } \\
\text { R: GAGTGAGGAAGCCCAACC }\end{array}$ & $(\mathrm{ATC})_{7} \ldots(\mathrm{TC})_{23}$ & GU177204 & 56.0 \\
\hline
\end{tabular}




\section{Breeding design and husbandry}

In September 2006, the mating design was prepared in a $3 \times 3$ full diallel design as fol-

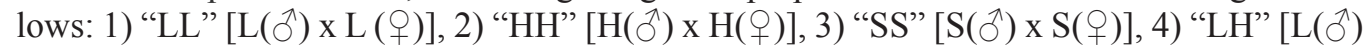

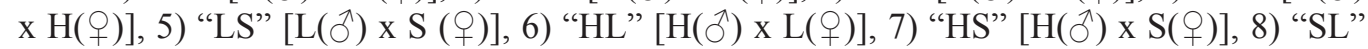

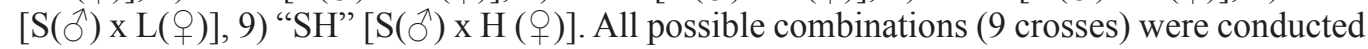
(3 purebreds and 6 crossbreds). For each type of cross, there were 10 groups each, including 1 male and 3 females.

After mating, the females from each group migrated to the pond (measuring $10 \times 8 \times 1$ $\mathrm{m}$; temperature range, $9^{\circ} \pm 0.5^{\circ} \mathrm{C}$, salinity, $30 \%$ ) indoor for overwintering in November 2006 . Females extruded a fertilized brood of eggs (a sponge) with stored sperm, and then were transported separately to the indoor pond (measuring $3 \times 4 \times 1 \mathrm{~m}$; temperature range, $22^{\circ}-26^{\circ} \mathrm{C}$, salinity, $30 \%$ ) for hatchlings in March 2007. Here, they underwent 4 zoeal stages, 1 megalopal stage, and 2 crab stages. From April 10 to 16, 2007, 38 females produced larvae separately. We obtained 38 families. Families were reared separately, but under the same conditions until they reached the second crab stage. The number of water exchanges increased was in accordance with the growth of individuals in the indoor pond. During this stage, the pond outdoor was divided into several small ponds equally with nets and randomly sampled. Next, 1500 second crabs from each family were moved to the small ponds separately. We chose 27 of 38 families to examine each mating combination ( 3 purebreds and 6 crossbreeds), including 3 families. Twenty-seven families were reared and managed in the same manner, including food administration and fishery drugs. The amount and the proportion of the food were adjusted daily based on different growth stages.

\section{Measurements of growth and survival}

Growth measurements were obtained for 30 crabs selected randomly from each of the 27 families. At 80, 100, and 120 days, we measured body weight (in grams), full carapace width $(\mathrm{mm})$, carapace width $(\mathrm{mm})$, carapace length $(\mathrm{mm})$, and body height $(\mathrm{mm})$. The survival rate of each family was estimated when crabs were harvested.

Survival rate $(\mathrm{S})=a / b \times 100 \%$, where $a$ and $b$ represent the harvest number and second crabs from each family moved to the small ponds, respectively.

\section{Statistical analyses}

The genetic differentiation coefficient $\left(F_{\mathrm{ST}}\right)$ was calculated to test the significance of population differentiation among 3 populations using FSTAT2.9.2 and genetic distance among 3 populations were estimated using the POPGENE 1.31 software.

Heterosis was calculated as the difference between the mean performance of the hybrid families (both combined and separately) and the mean performance of their purebred parent lines, expressed as a percentage of the mean performance of the parent lines (i.e., "midparent heterosis", Bourdon, 1997).

$$
H(\%)=\frac{\overline{F_{1}}-\frac{1}{2}\left(\overline{P_{1}}+\overline{P_{2}}\right)}{\frac{1}{2}\left(\bar{P}_{1}+\bar{P}_{2}\right)}
$$


where $F_{l}, P_{l}$, and $P_{2}$ represent the average values for the filial (F1) generation, the value for parent 1 and the value for parent 2, respectively. Mid-parent heterosis was calculated for all growth traits and survival rate.

One-way analysis of variance was used to assess the significance of variation in growth measurements among the different crosses at 120 days. The Duncan multiple range test was then performed for the traits showing significant variation among families. A significance level of $\alpha=0.05$ was used.

\section{RESULTS}

\section{Genetic differentiation among three populations}

The results showed that three population pairs were genetically different as demonstrated by highly significant genetic differentiation test results $(\mathrm{P} \leq 0.01)$. The pairwise $F_{\text {ST }}$ values among the three populations were significantly higher than $0(\mathrm{P}=0.0000)$ for every population pair, ranging from 0.0810 to 0.1083 (Table 2). The $F_{\mathrm{ST}}$ value was highest between the populations of $\mathrm{S}$ and $\mathrm{L}$, and lowest between the populations of $\mathrm{S}$ and $\mathrm{H}$. The range of genetic distance among three populations was 0.3457-0.5179 (Table 3). The genetic distance was highest between the populations of $\mathrm{S}$ and $\mathrm{L}$ and minimum between the populations of $\mathrm{S}$ and $\mathrm{H}$.

\begin{tabular}{l} 
Table 2. $F_{\text {ST }}$ values for pairwise comparison among different populations of Portunus trituberculatus based on \\
8 microsatellite primers. \\
\hline Population \\
\hline S
\end{tabular}

Table 3. Inter-population genetic identification (upper triangle) and genetic distance (lower triangle) among three populations of Portunus trituberculatus based on 8 microsatellite primers.

\begin{tabular}{lccc}
\hline Population & S & H & L \\
\hline S & - & 0.7077 & 0.5958 \\
H & 0.3457 & - & 0.6551 \\
L & 0.5179 & 0.4229 & - \\
\hline$* * \mathrm{P}<0.01$. & & &
\end{tabular}

\section{Difference of performance between crosses}

\section{Eighty days old}

At 80 days of age (Table 4 ), the mean body weight of the $\mathrm{F}_{1}$ generation ranged from $17.87 \pm 5.03$ to $18.55 \pm 5.05 \mathrm{~g}$ for purebreds and $18.39 \pm 6.84$ to $20.55 \pm 5.51 \mathrm{~g}$ for crossbreds. The mean body height of the $F_{1}$ generation ranged from $16.55 \pm 1.88$ to $18.08 \pm 1.81$ $\mathrm{mm}$ for purebreds and $17.18 \pm 2.53$ to $18.67 \pm 1.98 \mathrm{~mm}$ for crossbreds. The mean carapace 
length of the $\mathrm{F}_{1}$ generation ranged from $30.28 \pm 4.15$ to $31.78 \pm 3.24 \mathrm{~mm}$ for purebreds and $30.63 \pm 4.88$ to $33.23 \pm 3.51 \mathrm{~mm}$ for crossbreds. The mean carapace width of the $\mathrm{F}_{1}$ generation ranged from $28.84 \pm 2.78$ to $32.45 \pm 3.28 \mathrm{~mm}$ for purebreds and $30.84 \pm 2.78$ to $32.84 \pm 3.15 \mathrm{~mm}$ for crossbreds. The mean full carapace width of $\mathrm{F}_{1}$ generation ranged from $65.74 \pm 9.49$ to $68.20 \pm 5.80 \mathrm{~mm}$ for purebreds and $66.25 \pm 10.83$ to $68.89 \pm 5.21 \mathrm{~mm}$ for crossbreds.

Table 4. Values of the 5 growth traits measured in all nine crossed strains and estimates of the degree of heterosis exhibited by the F1 generation of crossbred populations (i.e., crosses of different geographical populations).

\begin{tabular}{|c|c|c|c|c|c|c|c|c|c|c|}
\hline \multirow[t]{2}{*}{ Traits } & \multirow[t]{2}{*}{ Mating } & \multicolumn{3}{|c|}{80 days old } & \multicolumn{3}{|c|}{100 days old } & \multicolumn{3}{|c|}{120 days old } \\
\hline & & & SD & $H(\%)$ & & SD & $H(\%)$ & & SD & $H(\%)$ \\
\hline \multicolumn{11}{|c|}{ Full carapace width (mm) } \\
\hline & LL & 65.74 & 9.49 & - & 87.13 & 10.91 & - & 113.46 & 7.29 & - \\
\hline & SS & 66.34 & 7.77 & - & 94.43 & 13.62 & - & 118.53 & 7.93 & - \\
\hline & $\mathrm{HH}$ & 68.20 & 5.80 & - & 91.61 & 10.93 & - & 103.18 & 9.82 & - \\
\hline & SL & 66.25 & 10.83 & 0.32 & 91.17 & 11.40 & 0.43 & 118.64 & 13.11 & 2.28 \\
\hline & LS & 68.33 & 7.72 & 3.47 & 90.89 & 9.81 & 0.12 & 118.18 & 8.79 & 1.88 \\
\hline & HL & 67.13 & 5.14 & 0.24 & 89.93 & 10.88 & 0.63 & 108.89 & 8.04 & 0.53 \\
\hline & LH & 68.47 & 8.46 & 2.24 & 92.23 & 9.78 & 3.20 & 110.78 & 7.18 & 2.27 \\
\hline & $\mathrm{SH}$ & 68.89 & 5.21 & 2.40 & 95.47 & 10.76 & 2.63 & 112.21 & 9.33 & 1.22 \\
\hline & HS & 67.93 & 5.98 & 0.98 & 93.98 & 9.24 & 1.03 & 111.49 & 8.39 & 0.57 \\
\hline \multicolumn{11}{|c|}{ Carapace width (mm) } \\
\hline & LL & 28.84 & 2.78 & - & 41.67 & 4.45 & - & 55.00 & 3.89 & - \\
\hline & SS & 32.45 & 3.28 & - & 45.74 & 7.96 & - & 57.81 & 3.86 & - \\
\hline & $\mathrm{HH}$ & 31.73 & 3.32 & - & 42.98 & 4.77 & - & 52.04 & 4.72 & - \\
\hline & SL & 31.31 & 4.69 & 2.17 & 44.92 & 4.44 & 2.78 & 56.59 & 7.11 & 0.33 \\
\hline & LS & 32.24 & 3.66 & 5.20 & 44.44 & 4.54 & 1.68 & 56.65 & 4.13 & 0.43 \\
\hline & HL & 30.84 & 2.78 & 1.83 & 43.10 & 3.39 & 1.80 & 52.15 & 3.83 & -1.91 \\
\hline & LH & 31.58 & 3.86 & 4.27 & 43.31 & 4.16 & 2.32 & 54.15 & 3.26 & 1.18 \\
\hline & SH & 32.84 & 3.15 & 2.34 & 45.14 & 3.89 & 1.76 & 55.76 & 4.15 & 1.52 \\
\hline & HS & 32.13 & 3.02 & 1.25 & 44.98 & 3.54 & 1.19 & 55.46 & 4.37 & 0.97 \\
\hline \multicolumn{11}{|c|}{ Carapace length (mm) } \\
\hline & LL & 30.28 & 4.15 & - & 40.33 & 4.29 & - & 51.92 & 3.23 & - \\
\hline & SS & 30.41 & 3.08 & - & 43.91 & 6.03 & - & 55.27 & 3.25 & - \\
\hline & $\mathrm{HH}$ & 31.78 & 3.24 & - & 42.16 & 4.27 & - & 48.94 & 3.83 & - \\
\hline & SL & 30.63 & 4.88 & 0.94 & 43.49 & 4.05 & 3.52 & 53.93 & 5.65 & 0.63 \\
\hline & LS & 32.11 & 3.19 & 5.82 & 43.53 & 5.93 & 3.34 & 53.54 & 3.72 & -0.10 \\
\hline & HL & 31.33 & 2.37 & 0.97 & 40.88 & 3.49 & -0.88 & 50.17 & 3.54 & -0.52 \\
\hline & LH & 33.23 & 3.51 & 5.89 & 42.68 & 3.11 & 3.47 & 51.29 & 2.82 & 1.71 \\
\hline & $\mathrm{SH}$ & 31.91 & 3.84 & 2.62 & 43.94 & 3.24 & 2.10 & 52.92 & 3.45 & 1.56 \\
\hline & HS & 31.35 & 3.72 & 0.82 & 43.56 & 3.04 & 1.22 & 52.57 & 3.14 & 0.89 \\
\hline \multicolumn{11}{|c|}{ Body height (mm) } \\
\hline & LL & 16.97 & 2.38 & - & 22.16 & 2.28 & - & 28.79 & 2.36 & - \\
\hline & SS & 16.55 & 1.88 & - & 24.11 & 3.21 & - & 29.60 & 1.91 & - \\
\hline & $\mathrm{HH}$ & 18.08 & 1.81 & - & 23.16 & 2.13 & - & 27.07 & 2.43 & - \\
\hline & SL & 17.18 & 2.53 & 2.51 & 25.09 & 2.12 & 4.13 & 30.10 & 3.00 & 3.10 \\
\hline & LS & 17.95 & 2.00 & 5.84 & 24.02 & 2.20 & 3.83 & 30.10 & 2.18 & 3.10 \\
\hline & HL & 17.60 & 1.59 & 0.43 & 23.00 & 1.69 & 1.50 & 28.10 & 1.80 & 0.61 \\
\hline & LH & 18.67 & 1.98 & 6.53 & 23.46 & 2.48 & 3.53 & 28.55 & 2.09 & 2.22 \\
\hline & SH & 17.84 & 1.84 & 3.03 & 24.15 & 2.58 & 2.18 & 28.90 & 2.05 & 1.99 \\
\hline & HS & 17.41 & 1.68 & 0.55 & 23.90 & 2.15 & 1.12 & 28.54 & 1.94 & 0.72 \\
\hline \multicolumn{11}{|c|}{ Body weight (g) } \\
\hline & LL & 18.34 & 8.35 & - & 43.94 & 7.69 & - & 88.94 & 15.08 & - \\
\hline & SS & 17.87 & 5.03 & - & 51.77 & 15.04 & - & 104.80 & 17.38 & - \\
\hline & $\mathrm{HH}$ & 18.55 & 5.05 & - & 44.86 & 13.21 & - & 72.13 & 12.67 & - \\
\hline & SL & 19.06 & 7.78 & 5.27 & 48.95 & 11.62 & 2.29 & 101.10 & 17.80 & 4.37 \\
\hline & LS & 20.55 & 5.51 & 13.50 & 48.46 & 13.41 & 1.26 & 97.67 & 18.41 & 0.83 \\
\hline & HL & 18.53 & 3.03 & 0.46 & 45.00 & 13.86 & 1.35 & 81.50 & 13.45 & 1.20 \\
\hline & LH & 20.30 & 8.35 & 10.08 & 45.30 & 7.39 & 1.94 & 83.21 & 13.14 & 3.32 \\
\hline & $\mathrm{SH}$ & 18.90 & 6.33 & 3.79 & 49.14 & 14.83 & 1.71 & 90.34 & 15.12 & 2.12 \\
\hline & HS & 18.39 & 6.84 & 0.99 & 48.67 & 13.18 & 0.73 & 89.24 & 14.33 & 0.88 \\
\hline
\end{tabular}




\section{One hundred days old}

At 100 days of age (Table 4), the mean body weight of the $\mathrm{F}_{1}$ generation ranged from $43.94 \pm 7.69$ to $51.77 \pm 15.04 \mathrm{~g}$ for purebreds and $45.00 \pm 13.86$ to $49.14 \pm 14.83 \mathrm{~g}$ for crossbreds. The mean body height of the $\mathrm{F}_{1}$ generation ranged from $22.16 \pm 2.28$ to $24.11 \pm 3.21$ $\mathrm{mm}$ for purebreds and $23.00 \pm 1.69$ to $24.15 \pm 2.58 \mathrm{~mm}$ for crossbreds. The mean carapace length of the $\mathrm{F}_{1}$ generation ranged from $40.33 \pm 4.29$ to $43.91 \pm 6.03 \mathrm{~mm}$ for purebreds and $40.88 \pm 3.49$ to $43.94 \pm 3.24 \mathrm{~mm}$ for crossbreds. The mean carapace width of the $\mathrm{F}_{1}$ generation ranged from $41.67 \pm 4.45$ to $45.74 \pm 7.96 \mathrm{~mm}$ for purebreds and $43.10 \pm 3.39$ to $45.14 \pm 3.89$ $\mathrm{mm}$ for crossbreds. The mean full carapace width of the $\mathrm{F}_{1}$ generation ranged from $87.13 \pm$ 10.91 to $94.43 \pm 13.62 \mathrm{~mm}$ for purebreds and $90.89 \pm 9.81$ to $95.47 \pm 10.76 \mathrm{~mm}$ for crossbreds.

\section{One hundred and twenty days old}

At 120 days of age (Table 4), the mean body weight of the $\mathrm{F}_{1}$ generation ranged from $72.13 \pm 12.67$ to $104.80 \pm 17.38 \mathrm{~g}$ for purebreds and $81.50 \pm 13.45$ to $101.10 \pm 17.80 \mathrm{~g}$ for crossbreds. The mean body height of the $\mathrm{F}_{1}$ generation ranged from $27.07 \pm 2.43$ to $29.60 \pm$ $1.91 \mathrm{~mm}$ for purebreds and $28.10 \pm 1.80$ to $30.10 \pm 3.00 \mathrm{~mm}$ for crossbreds. The mean carapace length of the $\mathrm{F}_{1}$ generation ranged from $48.94 \pm 3.83$ to $55.27 \pm 3.25 \mathrm{~mm}$ for purebreds and $50.17 \pm 3.54$ to $53.93 \pm 5.65 \mathrm{~mm}$ for crossbreds. The mean carapace width of the $\mathrm{F}_{1}$ generation ranged from $52.04 \pm 4.72$ to $57.81 \pm 3.86 \mathrm{~mm}$ for purebreds and $52.15 \pm 3.83$ to $56.65 \pm 4.13$ $\mathrm{mm}$ for crossbreds. The mean full carapace width of the $\mathrm{F}_{1}$ generation ranged from $103.18 \pm$ 9.82 to $118.53 \pm 7.93 \mathrm{~mm}$ for purebreds and $108.89 \pm 8.04$ to $118.64 \pm 13.11 \mathrm{~mm}$ for crossbreds.

\section{Survival rate}

The survival rates of the $\mathrm{F}_{1}$ generation ranged from $10.40 \pm 3.21$ to $11.24 \pm 2.13 \%$ for purebreds and $9.97 \pm 2.78$ to $15.81 \pm 5.24 \%$ for crossbreds (Table 5). There were no significant differences between the purebreds and crossbreds.

\begin{tabular}{|c|c|c|c|c|c|c|c|c|c|}
\hline \multirow[t]{2}{*}{ Survival rate } & \multicolumn{9}{|c|}{ Cross type } \\
\hline & SL & LL & SS & $\mathrm{HH}$ & LS & $\mathrm{HL}$ & LH & SH & HS \\
\hline Mean & 15.81 & 10.40 & 11.24 & 10.82 & 9.97 & 14.43 & 11.01 & 11.24 & 12.12 \\
\hline SD & 5.24 & 3.21 & 2.13 & 2.94 & 2.78 & 4.36 & 5.12 & 4.56 & 3.72 \\
\hline$H(\%)$ & 46.12 & - & - & - & -7.85 & 36.00 & 3.75 & 1.90 & 9.88 \\
\hline
\end{tabular}

\section{Heterosis}

The results revealed significant heterosis in growth rates for all measured variables among the 6 crossbred lines (compared with the purebred lines, Table 4). At 80 days of age, the extent of heterosis was strongest $(0.24-13.50 \%)$ and there was stronger heterosis observed in the LS strain than in the SL strain for all 5 growth traits (Table 1). By 100 days of age, however, heterosis was weaker ( -0.88 to $4.13 \%$ ) and there was evidence of hybrid weakness in carapace length (Table 4). Similar results were evident at 120 days of age, heterosis was weaker (-1.91 to $4.37 \%$ ), and evidence of hybrid weakness in both carapace length and carapace width was 
observed (Table 4). We found that heterosis for survival rates varied from (-7.85 to $46.12 \%)$ and was strongest in the SL strain, with evidence of hybrid weakness in the LS (Table 5).

\section{Analysis of variance of first filial generations}

Analysis of variance revealed that growth traits differed significantly among the 9 populations of first filial generations (Table 6). There were no significant differences between $\mathrm{SL}$ and SS in 5 growth traits. However, there were significant $(\mathrm{P} \leq 0.01)$ differences between SL and LL. There were significant differences between LS and LL for the 5 growth traits.

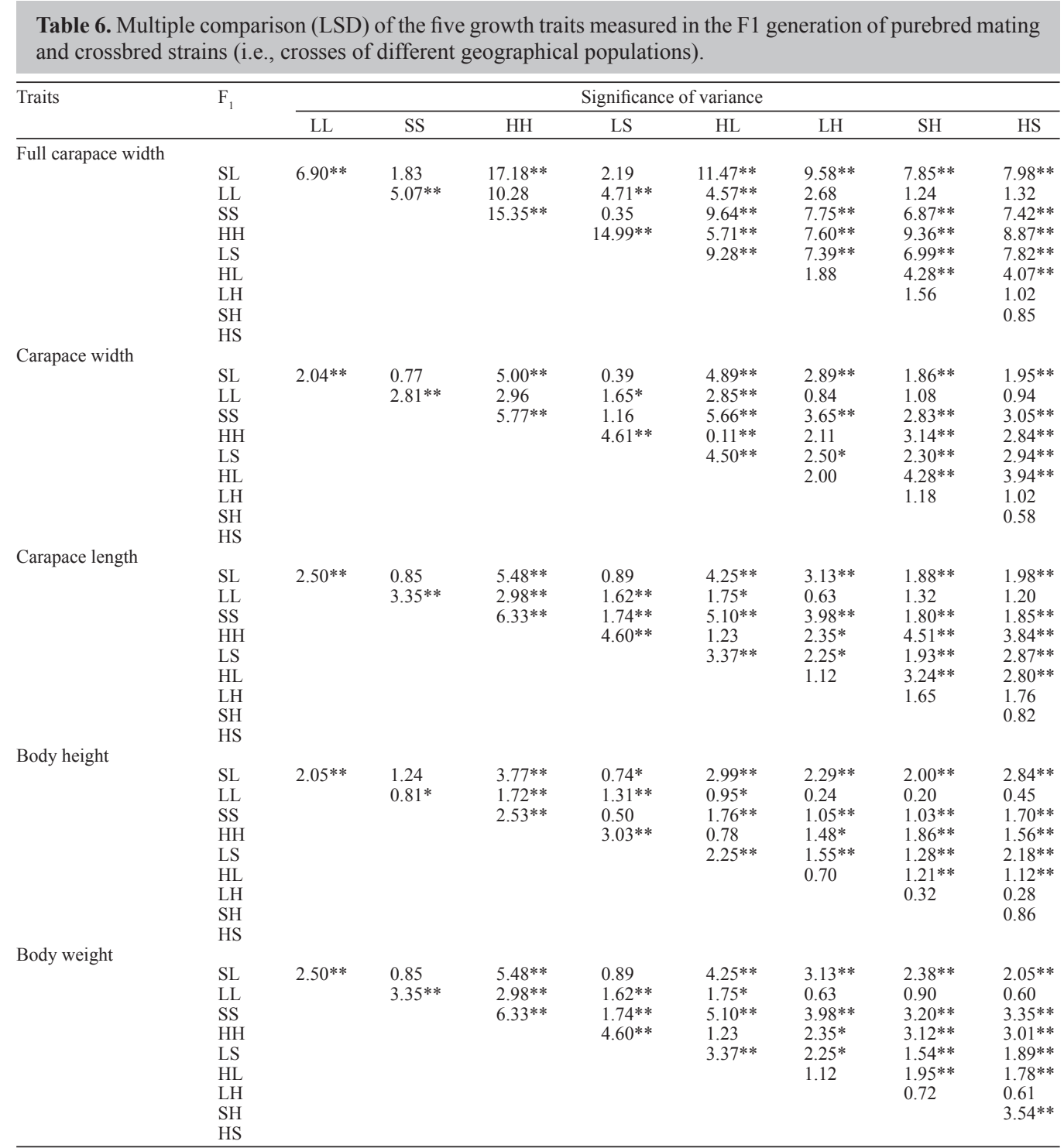

**Highly significant difference, $\mathrm{P}<0.01$; ${ }^{*}$ significant difference, $\mathrm{P}<0.05$. 


\section{DISCUSSION}

The genetic traits of domestic farm animals can be improved through inter-species hybridization or intra-species crossbreeding among geographically distinct sub-populations. Generally, the hybrids excel over their parents in many measures of viability as a result of crossing of genetically divergent populations or between inbred lines (Falconer and Mackay, 1989). The phenotypic advantage conferred by quantitative genetic traits is directly related to gene frequencies in the crossbred populations. The larger the difference in gene frequencies, the greater the expected hybrid advantage (Falconer and Mackay, 1996). Thus, the recombination of gametes during crossing of genetically different parental lines can produce heterosis in the resulting offspring (Tian et al., 2008).

Crossbreeding programs to enhance genetic viability in the farming of crustaceans and fish have shown positive results in recent years. For example, the F1 hybrids of channel catfish and blue catfish were shown to have higher dress-out and fillet percentages than in the parents (Argue et al., 2003). In another study, the reciprocal hybrids of 3 brook trout strains showed heterosis for weight varying from 4.9 to $23.8 \%$ higher than the parental lines (Crespel et al., 2012). In addition, crosses between 2 geographic subspecies of the bay scallop Argopecten irradians improved total yield and resulted in positive heterosis in the F1 generation for shell length, shell height, shell width, total weight, and adductor weight (Zheng et al., 2011). Another study revealed that F1 hybrids of geographically distinct populations of Chinese shrimp improved growth performance (Tian et al., 2008).

This is the first study to investigate heterosis in the swimming crab. Estimates of $F_{\mathrm{ST}}$ (0.0810-0.1083) showed that the genetic structure changed among the populations. Heterosis ranged from 0.24 to $13.50 \%$ at 80 days, from -0.88 to $4.13 \%$ at 100 days, and from -1.91 to $4.37 \%$ at 120 days, but there was also hybrid weakness for carapace length and carapace width. Heterosis varied in different combinations and for different traits. Our results showed that the genetic distance between the parents was positively correlated with heterosis. This has also been observed in fish. For example, Wang and Xia (2002) found a positive relationship between genetic distances and heterosis in growth of 1 intraspecific and 2 interspecific fish hybrids. There were significant correlations between heterosis and molecular genetic distances in crossbreds of the guppy Poecilia reticulata reported by Shikano and Taniguchi (2003). However, studies conducted in plants showed inconsistent results. For example, genetic distance was not correlated with heterosis for rice hybrid seed yield (Teklewold and Becker, 2006) and was negatively correlated with heterosis of yield (Singh et al., 2011).

Our results indicate that crossbreeding among geographically and genetically distinct populations of swimmer crabs is a viable method for selecting new strains that are more robust and can withstand the effects of intensive aquaculture.

\section{ACKNOWLEDGMENTS}

Research supported by grants from the Hi-Tech Research and Development Program of China ("863") (\#2012AA10A409), the Independent Innovation Foundation of Shandong Province, \#2013CXC80202), and the Natural Science Foundation of Shandong Province (\#ZR2013CQ046). 


\section{REFERENCES}

Argue BJ, Liu Z and Dunham RA (2003). Dress-out and fillet yields of channel catfish, Ictalurus punctatus, blue catfish, Ictalurus furcatus, and their F1, F2 and backcross hybrids. Aquaculture 228: 81-90.

Benzie JAH, Kenway M and Ballment E (1995). Interspecific hybridization of the tiger prawns Penaeus monodon and Penaeus esculentus. Aquaculture 133: 103-111.

Bierne N, Beuzart I and Vonan V (2000). Microsatellite-associated heterosis in hatchery-propagated stocks of the shrimp Penaeus stylirostris. Aquaculture 184: 203-219.

Bourdon RM (1997). Understanding Animal Breeding. Prentice-Hall, Upper Saddle River.

Colleen AB, John WH and Daniel DHC (2004). Performance and heterosis in farmed and wild Chinook salmon (Oncorhynchus tshawytscha) hybrid and purebred crosses. Aquaculture 235: 249-262.

Crespel A, Audet C, Bernatchez L and Garant D (2012). Effects of rearing environment and strain combination on heterosis in brook trout. N. Am. J. Aquacult. 27: 188-198.

Cruz P and Ibarra AM (1997). Larval growth and survival of two catarina scallop (Argopecten circularis, Sowerby, 1835) population and their reciprocal crosses. J. Exp. Marin. Biol. Ecol. 212: 95-110.

English LJ, Maguire GB and Ward RD (2000). Genetic variation of wild and hatchery populations of the Pacific oyster, Crassostrea gigas (Thunberg), in Australia. Aquaculture 187: 283-298.

Falconer DS and Mackay TFC (1989). Introduction to Quantitative Genetics, 3rd edn. Longman, New York.

Falconer DS and Mackay TFC (1996). Introduction to Quantitative Genetics, 4th edn. Pearson Education, Ltd., Essex, 464.

Fishery Bureau, Ministry of Agriculture PRC (FBMAPRC) (2010). China fisheries yearbook 2010. Chinese Agriculture Express, pp. 25.

Gao BQ, Liu P, Li J and Ma S (2007). Analysis of morphological variations among four wild populations of Portunus trituberculatus. J. Fish. Sci. China 14: 223-228.

Lawrence AL, Bray WA and Wilkenfeld JS (1994). Successful inter specific cross of two species of marine shrimp Penaens stylirostris and Penaens setiferus in captivity. 15th Annual Conference of the World Aquaculture Society, Vancouver BC, 39.

Lin MN, Ting YY and Han YI (1988). Hybridization of two close-thelycum penaeid species Penaeus Monodon x $P$. penicillatus and P. penicillatus x P. monodon, by means of spermatophore transplantation. Bull. Taiwan Fish. Res. 45: 83-101.

Liu P and Xu HS (2000). RAPD analysis of genetic diversity in two Huang-Bo Sea stock families of Penaeus chinensis. Mar. Fish. Res. 21: 13-21.

Liu XL, Chang YQ and Xiang JH (2003). Studies on hybridization effects of different geographic population of Chlamys farreri. Acta Oceanol. Sin. 22: 255-263.

Misamore M and Browdy CL (1997). Evaluating hybridization potential between Penaeus setiferus and Penaeus vannamei through natural mating, artificial insemination and in vitro fertilization. Aquaculture 150: 1-10.

Shikano T and Taniguchi N (2003). DNA markers for estimation of inbreeding depression and heterosis in the guppy Poecilia reticulata. Aquacult. Res. 34: 905-911.

Singh VK, Upadhyay P, Sinha P, Mall AK, et al. (2011). Prediction of hybrid performance based on the genetic distance of parental lines in two-line rice (Oryza sativa L.) hybrids. J. Crop Sci. Biotechnol. 14: 1-10.

Teklewold A and Becker HC (2006). Comparison of phenotypic and molecular distances to predict heterosis and F1 performance in Ethiopian mustard (Brassica carinata A. Braun). Theor. Appl. Genet. 112: 752-759.

Tian Y, Kong J, Li WD, Luan S, et al. (2008). Genetic improvement on Chinese shrimp (Fenneropenaeus chinensis): growth and viability performance in F1 hybrids of different populations. Chin. J. Oceanol. Limnol. 26: 369-374.

Wang GL, Jin S, Li Z and Chen YE (2006). On histopathology and ultrastructure of portunus trituberculatus suffered from "emulsion disease". Oceanol. Limnol. Sin. 37: 297-303.

Wang J and Xia D (2002). Studies on fish heterosis with DNA fingerprinting. Aquacult. Res. 33: 941-947.

Zheng HP, Xu F and Zhang GF (2011). Crosses between two subspecies of bay scallop Argopecten irradians and heterosis for yield traits at harvest. Aquacult. Res. 42: 602-612. 